\title{
Effects of Sn Dopant on Structural and Optical Properties of ZnO Thin Film Prepared by Sol-Gel Route
}

\author{
M.F. Malek ${ }^{1,2, a}$, M.H. Mamat ${ }^{1, b}$, N.D. Md $\operatorname{Sin}^{1, c}$ and M. Rusop ${ }^{1,2, d}$ \\ ${ }^{1}$ NANO-ElecTronic Centre (NET), Faculty of Electrical Engineering, Universiti Teknologi MARA \\ (UiTM), 40450 Shah Alam, Selangor, Malaysia \\ ${ }^{2}$ NANO-SciTech Centre (NST), Institute of Science (IOS), Universiti Teknologi MARA (UiTM), \\ 40450 Shah Alam, Selangor, Malaysia \\ afirz_solarzelle@yahoo.com, ${ }^{\mathrm{b}}$ hafiz_030@yahoo.com, ${ }^{\mathrm{c}}$ nordiyana86@yahoo.com, \\ 'rusop@salam.uitm.my
}

Keywords: ZnO; Sn; Sol-gel; Dip-coating

\begin{abstract}
Tin doped zinc oxide ( $\mathrm{Sn}: \mathrm{ZnO})$ thin films were prepared on glass substrates via sol-gel dip-coating technique starting from zinc acetate dehydrate, $\left(\mathrm{CH}_{3} \mathrm{CO}_{2}\right)_{2} \mathrm{Zn} \cdot 2 \mathrm{H}_{2} \mathrm{O}$ and tin chloride, $\mathrm{SnCl}_{2}$. The consequences of various $\mathrm{Sn}$ doping on the behavior of the film was investigated. The atomic percentages of dopant in $\mathrm{ZnO}$-based solution were $\left[\mathrm{Sn}^{4+}\right] /\left[\mathrm{Zn}^{2+}\right]$ which is between $0 \%$ and 4\%. The thin films were characterized using Field Emission Scanning Electron Microscope (FESEM) and UV-Vis-NIR spectrophotometer.
\end{abstract}

\section{Introduction}

ZnO-based thin films have received spacious attention due to their particular structural and optical characteristics which are widely adapted in numerous type of device fabrication, such as UV sensors [1], light emitting diodes and thin film solar cells [2]. The characteristics and properties of intrinsic and doped $\mathrm{ZnO}$ thin films have been tremendously investigated. Most of these investigations focused on various dopant such by using appropriate donor of group III elements like Aluminium (Al), Gallium (Ga), and Indium (In). In order to achieve higher conductivity of ZnO-based thin films, various tetravalent metal dopants are added to $\mathrm{ZnO}$ films, such as silicon (Si), germanium (Ge), tin (Sn), titanium (Ti), etc. Among these tetravalent metal dopants, $\mathrm{Sn}$ is a suitable material because it possess a good optical transmittance. Besides, $\mathrm{Sn}$ will becomes $\mathrm{Sn}^{4+}$ when it substitutes $\mathrm{Zn}^{2+}$ site in the $\mathrm{ZnO}$ crystal lattice. This will produce two more free electrons to contribute to the electric conduction. In the present work, our interest was focused on the structural and optical properties of $\mathrm{Sn}$-doped $\mathrm{ZnO}$ thin films. Several techniques were employed to produce intrinsic and doped $\mathrm{ZnO}$ films, including chemical vapor deposition (CVD) [3], sputtering, spray pyrolysis [4] and the sol-gel process. Among the preparation techniques of $\mathrm{ZnO}$ films, the sol-gel route represents an easy low cost and efficient route to coat large area surfaces for technological applications. In addition, this technique is one of the most promising in order to its simplicity, customizable micro/nano-structure, excellent control of stoichiometry of precursor solution, ease to compositional modifications and minimum variables to control the growth of film. Moreover, incorporation of dopants is easier in this technique.

\section{Experimental}

The $\mathrm{ZnO}$ based solution procedure has been reported before by the authors elsewhere [5,6]. In this experiment, tin (IV) chloride pentahydrate $\left(\mathrm{SnCl}_{4} .5 \mathrm{H}_{2} \mathrm{O}\right)$ was used as a dopant source. The $\left[\mathrm{Sn}^{4+}\right] /\left[\mathrm{Zn}^{2+}\right]$ nominal ratio was $0,1.0,2.0,3.0$ and $4.0 \%$. The solution that had been mixed was stirred and heated at $80{ }^{\circ} \mathrm{C}$ for 1 hour until it becomes clear and homogeneous. Then, the solution was sonicated at $50^{\circ} \mathrm{C}$ using ultrasonic water bath (Hwasin Technology Powersonic 405, $40 \mathrm{kHz}$ ). 
Dip-coating method was performed to obtain the thin films. Borosilicate glass was chosen as a substrate. All the substrates was being ultrasonically cleaned with acetone, methanol and distilled (DI) water before the coating process. The glass substrates were deposited into the precursor solution at constant speed of $40 \mathrm{~mm} / \mathrm{min}$. After the coating process, the thin films were immediately being heated to evaporate the solvent. The thin films were then undergo post-heating treatment at $500{ }^{\circ} \mathrm{C}$ in air ambient. The films structure morphology were characterised by Field Emission Scanning Electron Microscopy, FESEM (model: JEOL JSM 6701F). On the other hand, the optical properties were measured by UV-Vis-NIR spectrometer (model: Varian Cary 5000) in the wavelength range from 350 to $800 \mathrm{~nm}$.

\section{Structural Properties}

The surface morphologies of $\mathrm{Sn}$ doped $\mathrm{ZnO}$ thin films that were prepared at different dopant concentration between $0 \%$ and $4.0 \%$ are shown in Fig. 2 (50 k magnification; $5 \mathrm{kV}$ applied voltage). The FESEM images show that the films deposited from 0 to $3.0 \%$ are uniformly deposited with
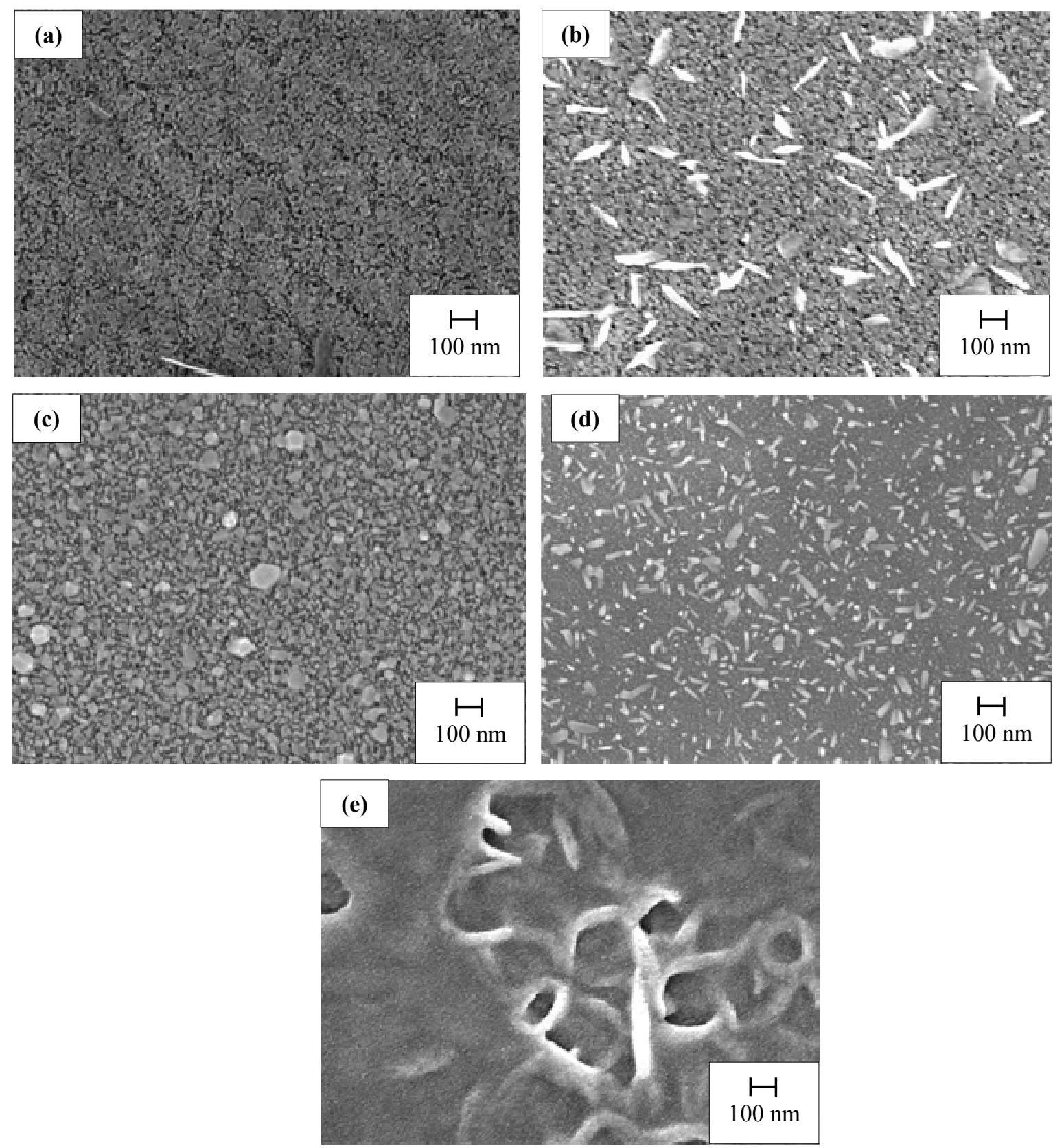

Fig.1, FESEM morphologies of Sn doped $\mathrm{ZnO}$ thin films at different dopant concentrations (a) $0 \%$, (b) $1.0 \%$, (c) $2.0 \%$, (d) $3.0 \%$ and (e) $4.0 \%$ 
nanoscale $\mathrm{ZnO}$ particles. Furthermore, the FESEM images show different morphologies of each film which depend on the concentration of Sn. A spherical grain structure was observed for undoped $\mathrm{ZnO}$ while the films doped at $1.0 \%$ of Sn revealed a flakes structure on a spherical grain. On the other hand, a faceted granular grain structure can be observed for films doped at $2 \%$. This faceted granular grain structure becomes into single nanorods alike. It was also observed that an agglomerated particles were formed which create a boundary between each other at higher $\mathrm{Sn}$ concentration which is $4.0 \%$. This might be originated from an increase in lattice strain/stress which is due to the difference in ionic radius between $\mathrm{Zn}^{2+}$ and $\mathrm{Sn}^{4+}[7]$.

\section{Optical Properties}

The optical transmittance spectra of $\mathrm{Sn}$ doped $\mathrm{ZnO}$ thin films as a function of a doping concentration in the wavelength range $(350-800 \mathrm{~nm})$ are shown in Fig. 2. It is shown that all films are highly transparent where the average optical transmittance values are higher than $90 \%$ in the visible region due to the homogeneous structure with uniform distributed particles in the film which reduces the optical scattering at the grain boundaries. The thin films had a sharp absorption onset at about $375 \mathrm{~nm}$ which is attributed to the intrinsic band gap of $\mathrm{ZnO}$. Besides, it can be observed that the optical transmittance spectra of films represent a strong dependance on the Sn concentration. After doping, the transmittance decreased when the dopant concentration was being increased to $2 \%$. On the other hand, we note that the transmittance increased again when the concentration of $\mathrm{Sn}=3.0 \%$ which might attributed to the presence of the interference fringes characteristics of uniform thickness and homogenous layers. However, the transmittance of the doped films always lower than those of undoped ones. The decrement of the transmittance after doping might be due to the increase of the thickness.

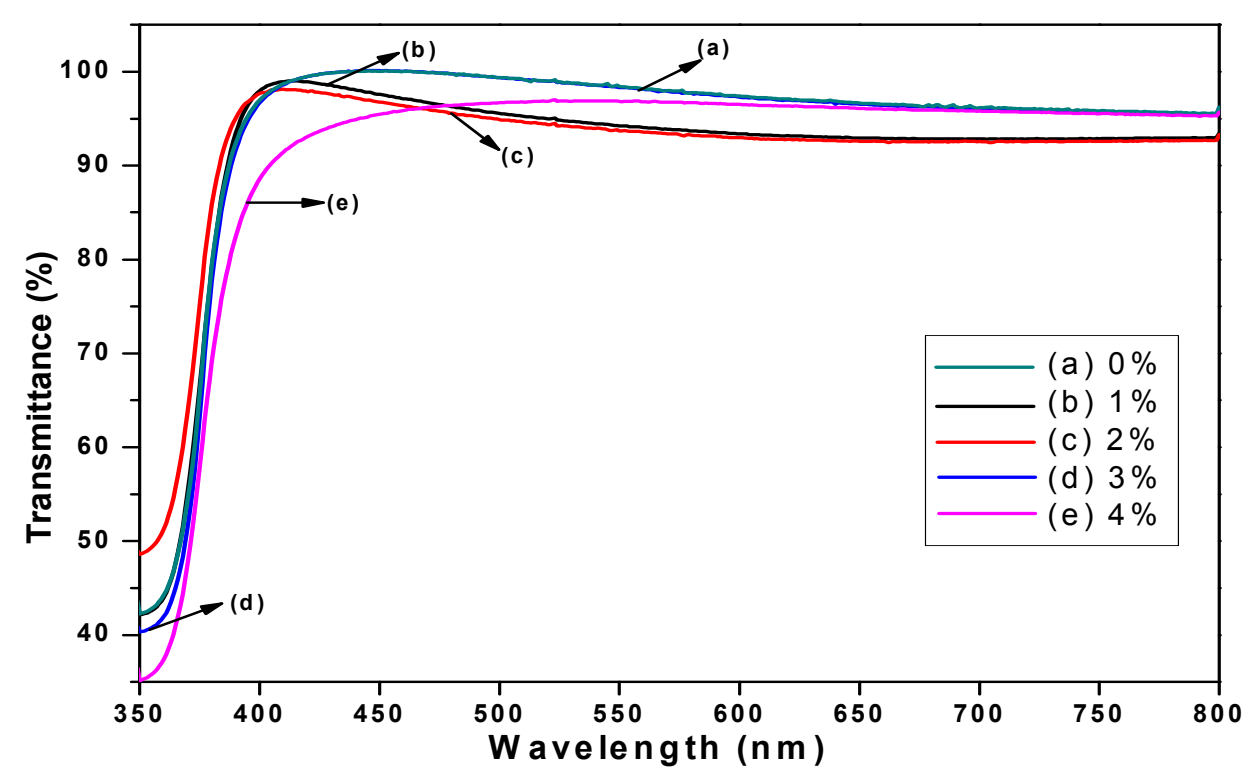

Fig. 2, Transmittance spectra of $\mathrm{Sn}$ doped $\mathrm{ZnO}$ thin films at different dopant concentrations (a) $0 \%$, (b) $1.0 \%$, (c) $2.0 \%$, (d) $3.0 \%$ and (e) $4.0 \%$

Band gap energies, $E_{g}$ estimated from the absorption edges of Sn doped $\mathrm{ZnO}$ films are shown in Fig. 3. Similar to the structure of $\mathrm{ZnO}$, the $\mathrm{Sn}$ doped $\mathrm{ZnO}$ film has a direct band gap. The absorption edge for direct interband transition is given by Eqs. (1) and (2) below [8]:

$$
\begin{aligned}
& \alpha \mathrm{hv}=B\left(\mathrm{hv}-\mathrm{E}_{\mathrm{g}}\right)^{1 / 2} \\
& (\alpha \mathrm{hv})^{2}=B \sqrt{\mathrm{hv}-\mathrm{E}_{\mathrm{g}}}
\end{aligned}
$$


where $B$ is a constant for direct transition, and $h v$ is the photon energy. The value of absorption coefficient, $\alpha$ is determined from the transmittance spectra. The optical energy gap, $E_{g}$ can then be obtained from the intercept of $(\alpha h v)^{2}$ versus $h v$ for direct transitions. Better linearity for $(\alpha h v)^{2}$ versus $h v$ is observed as shown in Fig. 3 and the energy gap was obtained by extrapolating the linear absorption edge part of the curve using equation (1) and (2).

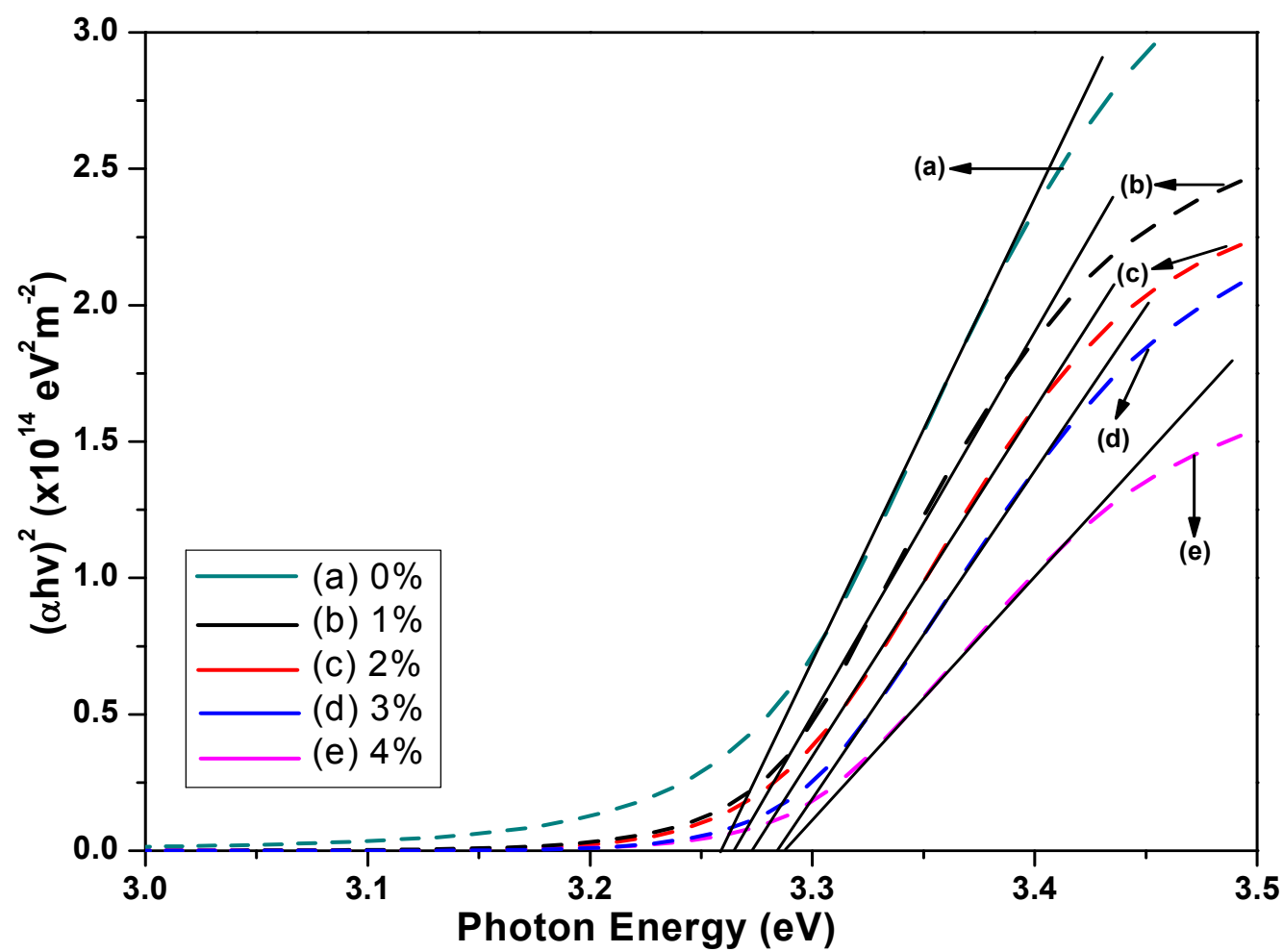

Fig. 3, Band gap energy of $\mathrm{Sn}$ doped $\mathrm{ZnO}$ thin films at different dopant concentrations (a) $0 \%$, (b) $1.0 \%$, (c) $2.0 \%$, (d) $3.0 \%$ and (e) $4.0 \%$

From the Tauc's plot, as the dopant concentration was being increased from 0 to $4.0 \%$, the optical band gap energy of the $\mathrm{ZnO}$ thin films is found to be 3.260, 3.265, 3.275, 3.285 and $3.290 \mathrm{eV}$ which closely agrees with the values reported by other researchers for polycrystalline $\mathrm{ZnO}$ thin films and published values of the $\mathrm{ZnO}$ electronic transition band gap data. It is noteworthy that a significant blue-shift in optical energy gap, $E_{g}$ was examined while the $\mathrm{Sn}$ contents were raised to $4.0 \%$. A slightly higher band gap of the films is due to the Burstein-Moss effect which described the blueshifting of the absorption edge of a degenerate semiconductor with an increasing carrier concentration $[9,10]$. According to the Moss-Burstein theory, the donor electrons occupy states at the bottom of the conduction band in heavily doped zinc oxide thin films. Since the Pauli principle prevents states from being doubly occupied and optical transitions are vertical, the valence electrons require extra energy to be excited to higher energy states in the conduction band. Therefore, the optical band gap of doped zinc oxide is broader than that of intrinsic zinc oxide films [10].

\section{Conclusion}

In this experiment, $\mathrm{Sn}$ doped zinc oxide were successfully prepared onto borosilicate glass substrates by sol-gel route. The introduction of $\mathrm{Sn}$ in the deposition process affected the growth of films because the thickness and the morphology of these thin layers varied when the amount of Sn was being varied. On the other hand, a blue-shift in the band gap energy is observed when the Sn dopant was being increased. Finally, we conclude that the structural and optical parameters of $\mathrm{ZnO}$ thin films were affected by Sn doping. 


\section{Acknowledgments}

This work was supported by grant no. 600-RMI/LRGS 5/3 (3/2013), 600-RMI/DANA 5/3/PSI (165/2013), 600-RMI/RACE 16/6/2 (9/2013) and by the MyBrain15 programme under the Ministry of Education (MOE). The authors would like to thank the Research Management Institute (RMI), Universiti Teknologi MARA (UiTM), Malaysia for their support. The authors thank Mrs. Nurul Wahida (UiTM Asst. Science Officer), Mr. Mohd Azlan Jaafar (UiTM technician) and Mr. Suhaimi Ahmad (UiTM technician) for their kind support of this research.

\section{References}

[1] M.H. Mamat, Z. Khusaimi, M.Z. Musa, M.F. Malek, M. Rusop, Fabrication of ultraviolet photoconductive sensor using a novel aluminium-doped zinc oxide nanorod-nanoflake network thin film prepared via ultrasonic-assisted sol-gel and immersion methods, Sens. Actuat. A 171 (2011) 241-247.

[2] M.F. Malek, M.Z. Sahdan, M.H. Mamat, M.Z. Musa, Z. Khusaimi, S.S. Husairi, N.D. Md Sin, M. Rusop, A novel fabrication of MEH-PPV/Al:ZnO nanorod arrays based ordered bulk heterojunction hybrid solar cells, Appl. Surf. Sci. 275 (2013) 75-83.

[3] X. Liu, X. Wu, H. Cao, R.P.H. Chang, Growth mechanism and properties of ZnO nanorods synthesized by plasma-enhanced chemical vapor deposition, J. Appl. Phys. 95 (2004) 3141-3147.

[4] M.W. Zhu, J.H. Xia, R.J. Hong, H. Abu-Samra, H. Huang, T. Staedler, J. Gong, C. Sun, X. Jiang, Heat-activated structural evolution of sol-gel-derived $\mathrm{ZnO}$ thin films, J. Cryst. Growth 310 (2008) 816-823.

[5] M.F. Malek, M.H. Mamat, M.Z. Sahdan, M.Z. Musa, Z. Khusaimi, M. Rusop, Influence of various sol concentrations on stress/strain and properties of $\mathrm{ZnO}$ thin films synthesised by sol-gel technique, Thin Solid Films 527 (2013) 102-109.

[6] M.F. Malek, M.H. Mamat, Z. Khusaimi, M.Z. Sahdan, M.Z. Musa, A.R. Zainun, A.B. Suriani, N.D. Md Sin, S.B. Abd Hamid, M. Rusop, Sonicated sol-gel preparation of nanoparticulate ZnO thin films with various deposition speeds: The highly preferred $c$-axis $\left(\begin{array}{lll}0 & 0 & 2\end{array}\right)$ orientation enhances the final properties, J. Alloys Comp. 582 (2014) 12-21.

[7] J.-H. Lee, B.-O. Park, Characteristics of Al-doped $\mathrm{ZnO}$ thin films obtained by ultrasonic spray pyrolysis: Effects of Al doping and an annealing treatment, Mater. Sci. Eng. B 106 (2004) 242-245.

[8] J. Tauc, R. Grigorovici, A. Vancu, Optical properties and electronic structure of amorphous germanium, Phys. Status Solidi 15 (1996) 627-637.

[9] T.S. Moss, The interpretation of the properties of indium antimonide, Proceedings of the Phys. Soc. Sec. B 67 (1954) 775-782.

[10] E. Burstein, Anomalous optical absorption limit in InSb," Phys. Rev. 93 (1954) 632-633. 